\title{
LÉXICO OBSCENO E GÍRIAS PAULISTANAS: UM ESTUDO NA PERSPECTIVA DA NEOLOGIA PRAGMÁTICA ${ }^{1}$
}

Flavio Biasutti Valadares*

Ruth Agostinho Araújo**

RESUMO: 0 artigo analisa léxico obsceno utilizado na posição de gíria configurada como resultado de neologia. Objetiva levantar léxico gírio a partir de construções neológicas, em específico quanto à escolha de léxico obsceno para interação, considerando fatores de ordem pragmática. Utiliza a pragmática, a sociolinguística interacional, a sociolinguística variacionista e a lexicologia como base teórica e adota como procedimento metodológico a recolha de gírias com usos de léxico obsceno em entrevistas orais. Conclui que a adoção de gírias na forma de léxico obsceno traduz um comportamento sociolinguístico e pragmático que remete a uma utilização na qual amplia o campo lexical, por meio de neologia pragmática, consolidando a noção conceitual de gíria e estabelecendo novas possibilidades de sentido para unidades lexicais obscenas em uso na nossa língua.

PALAVRAS-CHAVE: Pragmática; Neologia; Lexicologia; Gírias; Palavras obscenas.

\section{OBSCENE WORDS AND SLANG BY THE PEOPLE OF SÃO PAULO: A STUDY FROM THE POINT OF VIEW OF PRAGMATIC NEOLOGY}

\begin{abstract}
Obscene language used as slang is the result of neology. The paper surveys slang words from neologic constructions, particularly the choice of obscene words for interactivity based on pragmatic factors. Pragmatics, interactional sociolinguistics, variation sociolinguistics and lexicology constitute the basic theory. Methodology comprises the collection of obscene slang words in interviews. Results show that obscene slang words constitute a sociolinguistic and pragmatic behavior with a broadening of the lexical field through pragmatic neology. In fact, they consolidate the concept of slang and establish new meaning possibilities for obscene lexical units in the language.
\end{abstract}

KEYWORDS: Pragmatism; Neology; Lexicology; Slang; Obscene words.

\section{INTRODUÇÃO}

Neste artigo, levantam-se gírias advindas de léxico obsceno com vistas a evidenciar como um léxico gírio pode ser constituído a partir de produções neológicas, em específico quanto à escolha de tal léxico para interação, configurando uma possível mudança linguística, na esfera semântica, com a ampliação de significação do vocábulo gírio. Nesse aspecto, observa-se que a efemeridade das gírias promove que sua circulação seja ora maior, ora menor, o que contribui para se pensar que os léxicos obscenos que já são utilizados pelos falantes, em outros ambientes sociopragmáticos, podem migrar para um uso como gíria, assumindo novos contextos de sentido.

Posto isso, é importante frisar que a base teórica traz a pragmática como rotor, mas que a sociolinguística, a lexicologia e a neologia estão em conjunto formando o todo teórico-conceitual que sustenta as análises. Dessa

\footnotetext{
0 artigo compõe os trabalhos do grupo de pesquisa/CNPq - certificado pelo IFSP: Descrição do Português do Brasil, linha de pesquisa Estudos Analítico-Descritivos do Português do Brasil

* Doutor em Língua Portuguesa pela Pontíficia Universidade Católica (PUCSP). Pós-doutorado em Letras pela UPM-SP, Docente do IFSP/Campus São Paulo, Brasil. E-mail: flaviovaladares2@gmail.com

** Graduanda em Letras-Português/IFSP-Campus São Paulo. Orientanda de iniciação científica (PIBIFSP) na linha de pesquisa estudos analítico descritivos do português do Brasil.
} 
maneira, é necessário destacar alguns dos conceitos com os quais se trabalha neste artigo: léxico, gíria, neologismo, linguagem obscena e tabu linguístico.

Para léxico, são seguidos os postulados de Biderman (1996, 2001), Andrade (1998), Ortíz Alvarez (2004) e Guerra e Andrade (2012) para os quais reside a concepção de que se trata de vocabulários usados em situações sociolinguístico-culturais e comunicativas pelos usuários da língua e de que podem gerar novos vocábulos e/ou novos sentidos para os já existentes segundo o que os próprios falantes identifiquem nas interações como necessário.

Em relação à pesquisa, pode-se inferir que 0 conceito de léxico adotado caminha para 0 entendimento de que sua capacidade de conservar, por meio de seu repositório primeiro, 0 dicionário - mas atualmente em outros espaços também, em uma perspectiva de atualização de unidades lexicais do ponto de vista de construção do discurso -, a representação daquilo que opera para as relações de ordem política, social e econômica, em suas diversas esferas, manifesta uma espécie de reflexo da vida de um povo, com os registros que resultam de sua história e de seus contatos.

No caso da gíria, caracterizamô-la, como sustenta Preti (1984), um vocabulário especial, sendo considerado um signo de grupo, a princípio secreto, de domínio exclusivo de uma comunidade social restrita. Sob essa abordagem, a conceituação de gíria que consta em dicionários especializados, como 0 de Trask (2004), conduz a advogar em favor de uma forma linguística informal e frequentemente efêmera. Além disso, Trask (2004, p. 125) salienta que a gíria "tem sido descrita como língua em estado de jogo, isto é, as melhores gírias são pitorescas, exuberantes, espirituosas e fáceis de lembrar", o que corrobora a aproximação de seu conceito com 0 que se defende neste artigo.

Quanto ao neologismo, Alves (2002) afirma que todas as línguas os utilizam, já que a "criação neológica" faz parte da história das línguas e constitui uma evidência inequívoca de vitalidade, essencial para suprir as necessidades dos falantes e as condições de comunicação do idioma. Nesse ponto, depreendese que as entidades neológicas podem se configurar como formais, semânticas e pragmáticas e que, na visão adotada em nossa pesquisa, o estabelecimento do neologismo advém de conversas do cotidiano e das gírias.

Além disso, entende-se que a neologia semântica - estágio no qual há uma nova correspondência significante-significado - está ligada à neologia pragmática, quando resulta da passagem de um registro a outro, como se analisa neste artigo. Isso posto, é importante ressaltar que as línguas têm como característica universal a mudança e, em específico quanto à neologia, ampara a visão de que neologismos observados a partir do léxico obsceno cumprem duas linhas: a pragmática, pelo uso efetivo e real em contextos particulares, e a semântica por ampliar seu sentido para outros contextos de uso.

Sobre linguagem obscena, Preti (1984) esclarece que ela transita pelo campo dos tabus linguísticos, opondo-se à linguagem corrente e servindo "à descarga afetiva, à injúria, quer como índice de coloquialismo, quer como expressão carinhosa, perdida sua conotação injuriosa, em determinadas situações, onde se pretende forçar uma intimidade maior com o ouvinte" (PRETI, 1984, p. 27). Sob este viés, também, é importante trazer uma noção sobre tabu linguístico, já que o contraponto do que se propõe pode esbarrar na ideia de que a sociedade impõe sanções e restrições de ordem sociocultural e que isso pode gerar uma espécie de autorização ou não para se dizer palavrões. Orsi $(2011$, p. 336) assegura que 0 tabu linguístico

é decorrente das sanções, restrições e escrúpulos sociais; atua na não permissão ou na interdição de se pronunciar ou dizer certos itens lexicais aos quais se atribui algum poder e que, se violados, poderão trazer perseguições e castigos para quem os emprega. E, por estar em si também 0 impulso por ultrapassá-los, 0 ho- 
mem reverte as imposições e usa os palavrões e outras construções lexicais como forma de expressão de seus sentimentos e meio de subversão das proibições. (ORSI, 2011, p. 336)

Assim, nossa pesquisa ampara-se na base teórica da pragmática, da sociolinguística variacionista, da sociolinguística interacional e da lexicologia, bem como na conceituação atualmente estabelecida para gírias e também na visão sobre léxico obsceno, a fim de explicar como o uso do léxico obsceno em forma migrada de gírias pode manifestar escolhas neológicas do ponto de vista pragmático que remetem a uma amplificação do léxico de uma língua, via ampliação semântica, consolidando tanto a noção conceitual de gíria e quanto 0 estabelecimento de novas possibilidades de sentido.

\section{ASPECTOS TEÓRICO-METODOLÓGICOS}

Pragmática, de acordo com Crystal (2000, p. 240), estuda a linguagem sob o ponto de vista de seus usuários, "particularmente das escolhas que eles fazem, das restrições que eles encontram ao usar a linguagem em interações sociais, e dos efeitos que 0 uso da linguagem, por parte desses usuários, tem sobre os outros participantes no ato da comunicação". Levinson (2007) sustenta que a pragmática estuda as relações entre língua e contexto que são gramaticalizadas ou codificadas na estrutura de uma língua, como também a capacidade dos usuários da língua de emparelhar sentenças com os contextos em que elas seriam adequadas.

Nesse sentido, corroborando Crystal e Levinson, Barrere (2017) afirma que

a pragmática é o estudo do contexto e dos usos linguísticos que os indivíduos efetuam nos processos de interação verbal, dentro de um determinado evento comunicativo, e, sendo assim, é a partir daí que a pragmática se ocupa em estudar não apenas 0 uso, mas também 0 usuário e 0 contexto sociointeracional, revelando como os falantes de uma determinada língua fazem suas escolhas linguísticas em determinadas situações de comunicação, de modo que seus propósitos e atos de fala produzam determinados efeitos de sentido para os outros participantes. (BARRERE, 2017, p. 386)

Além da concepção pragmática aqui apresentada, é importante entender a contribuição da sociolinguística interacional para a pesquisa que, segundo Pereira (2002), focaliza interações situadas no relacionamento entre pessoas de grupos pequenos de comunidades específicas e estuda a relação entre língua e sociedade em situações de uso real, sendo possivel estudar tanto gêneros espontâneos, como conversa entre amigos, quanto gêneros institucionais, como consulta médica ou entrevista.

Sob a concepção de Gumperz (1982), em uma sumarização de seu postulado, propomos desenvolver a abordagem da sociolinguística interacional no âmbito dos processos comunicativos da interação humana para tratar de relações entre cultura, sociedade e indivíduo, buscando conferir na diversidade linguística e cultural presente no corpus selecionado seu impacto como mudança linguística. Igualmente, cabe explicitar que, para Gumperz (1982), existe um estabelecimento na sociolinguística interacional de uma ponte entre duas abordagens no estudo da diversidade: uma que focaliza práticas comunicativas moldadas por disposições para agir e perceber o mundo a partir de forças políticas e econômicas e os relacionamentos de poder e outra de natureza construtivista que reivindica que nossos mundos sociais são moldados por meio da interação.

A contribuição da teoria da variação e mudança linguística também fundamenta a pesquisa, principalmente no que se refere ao que Labov (2008, p. 19) explicita sobre mudança linguística. De acordo com 0 teórico, a mudança não pode ser abarcada fora da vida social da comunidade em que ela se efetiva. Ele ressalta três aspectos fundamentais a serem observados quando se pesquisa a mudança linguística: 1) origem 
das variações linguísticas, 2) difusão e propagação das mudanças linguísticas e 3 ) regularidade da mudança linguística.

Conforme Weinreich, Labov e Herzog (2006, p. 17), identificar os fatores condicionantes, a transição, o encaixamento, a avaliação e a implementação são primordiais para se sustentar se e em que fase se encontra uma mudança linguística. Especificamente no caso de léxico obsceno em uso como gírias, isso se torna crucial para provar os aspectos que se relacionam à estrutura sociolinguística, seus efeitos e razões para tais usos ocorrerem na língua, o que remete ao âmbito pragmático da adoção de tais léxicos como vocábulos gírios com ampliação semântica, caracterizando-0s como neologismos.

Posto isso, sustenta-se que a mudança linguística reverbera no sistema linguístico os níveis semânticos e pragmáticos, além dos fonológicos, morfossintáticos, e no léxico manifesta-se, em primeira instância, com maior visibilidade quanto a mudanças, principalmente se a neologia se ancorar em uma ampliação semântica, considerado o uso em termos pragmáticos a partir de contextos bastante específicos, como é o caso da proposta nesta pesquisa.

Em específico, traz-se sobre gírias o que assinala Trask (2004, p. 124): "costumam ser introduzidas por membros de um grupo social particular; podem continuar sendo típicas desse grupo e servir como uma de suas marcas de identidade ou, ao contrário, tornar-se mais amplamente conhecidas e usadas". Também, importa legitimar que o palavrão adotado em uso na posição de gíria atesta uma construção de identidade de grupo que alia a noção obscena do léxico gírio como conceito ao fato propriamente de, via seu uso, estabelecer um retorno à transgressão que a ideia de um tabu linguístico expede e que trafega embutido na concepção de gíria, ou seja, depreende-se que, no caso de uma palavra obscena, poderá haver ou não uma configuração de uso aceito conforme 0 contexto no qual seja utilizada. Em outras palavras, como confirma Preti (1984, p. 61), "a vida das palavras torna-se um reflexo da vida social e, em nome de uma ética vigente, proíbem-se ou liberam-se palavras, pro- cessam-se julgamentos de 'bons' ou 'maus' termos, apropriados ou inadequados aos mais variados contextos".

A partir disso, acentua-se, amparando-se em Bona (2008), que o palavrão é um item que pode não ser aceito pela sociedade e que um uso em público pode receber sanções dos grupos sociais, 0 que pode ser estendido à gíria como unidade lexical utilizada e aceita ou não a depender do contexto em que é utilizada, para além do grupo social fundante daquela criação, sendo que as palavras carregam, em si, valores, que podem se alterar segundo hábitos e costumes da sociedade, isto é, os grupos sociais têm a prerrogativa de deliberar sobre o que é ou não pejorativo frente a um uso obsceno, bem como situá-lo sob a ótica de censura ou condenação de uso socialmente.

Para além, na visão de Ullmann (1966, p. 245), a origem dos tabus linguísticos ocorre a partir de três fontes: 1) "o medo advindo da religião e das superstições"; 2) "assuntos delicados ou desagradáveis, como a doença e a morte"; 3) e "atos que transgridam as leis da decência e do decoro, como as que incluem referências sexuais". Considerado isso, Ullmann (1977, p. 206) classifica os tabus linguísticos como "tabus de medo ou superstição, diante de seres sobrenaturais, animais [...]; tabus de delicadeza, (envolvendo doenças, morte, defeitos físicos...); e tabus de decência ou decoro, abarcando determinadas partes e funções corporais e o sexo".

Por fim, ratifica-se, em termos teóricos, pela visão de Orsi (2011), que o léxico obsceno, quanto a seu estudo, esbarra no fato de ainda ser inserido num espectro de estudo secundário, prescindível e vulgar, até por isso a ideia de tabu linguístico. Por isso, entende-se ser importante mostrar como o léxico obsceno, em uso como vocábulo gírio, denota a efetividade de mudanças no comportamento psicossocial do brasileiro, especificamente do corpus selecionado, como se apresenta na análise, na seção seguinte.

Nessa perspectiva, para a análise, adota-se como procedimento metodológico a seleção de três palavras/expressões nas quais itens considerados tabus aparecem como gírias de um grupo, tendo como 
intuito evidenciar processos de mudança linguística desses léxicos obscenos e analisar a adoção dessas gírias na esteira da neologia pragmática para comprovar a construção de um padrão neológico de um grupo de fala. Para isso, foram escolhidas as palavras ou expressões que mais figuravam no léxico gírio da variante pesquisada e observada sua utilização em contexto espontâneo a partir de três entrevistas com um rapper da capital paulista, pertencente a uma comunidade de fala da periferia, todas elas publicadas no Youtube, mesmo que não fosse esse seu veículo de circulação inicial.

Além do recorte geográfico, a entrevista com o rapper permite um recorte social (de grupo), uma vez que a fala do entrevistado é repleta de gírias comuns à periferia e ao universo da música produzida nesses espaços. À luz da sociolinguística, foram levados em conta processos de mudança linguística com objetivo de demonstrar qual a sua relação com 0 que aqui se denomina neologismo semântico-pragmático. A transcrição dos trechos escolhidos foi feita a partir das regras utilizadas pelo projeto NURC (Norma Urbana Culta $)^{4}$ para possibilitar a observação das pausas e ênfases presentes no discurso.

\section{RESULTADO E DISCUSSÃO DOS DADOS}

Para a consecução da análise, a categorização apresenta 1) léxico obsceno como marcador de intensidade, 2) gíria com léxico obsceno funcionando como interjeição e 3) adjetivação a partir de léxico obsceno. A primeira entrevista é do programa de televisão Conversa com Bial, transmitido pela TV Globo; a segunda é uma entrevista feita pelo jornal francês Le Monde Diplomatique de ampla divulgação no Brasil, sendo 0 vídeo um conteúdo de circulação exclusiva do Youtube; e a terceira é uma entrevista para o Programa Freestyle, que é também nome do canal do Youtube que entrevista rappers e outros artistas de produção de arte periférica.

\footnotetext{
0 projeto NURC - Projeto de Estudo Coordenado da Norma Urbana Linguística Culta - constitui um banco de dados de falantes gravados em cinco capitais do Brasil (Porto Alegre, Recife, Rio de Janeiro, Salvador e São Paulo. Disponível em http://www. nurcrj.letras.ufrj.br/ Acesso em 24 set.2018.
}

Para fins de melhor compreender 0 contexto de cada uma, situam-se as três entrevistas ${ }^{5}$ em um continuum quanto ao grau de formalidade ou monitoramento da fala esperados. Desse modo, E1 figura como o meio de maior prestígio, por se tratar de uma emissora de TV conhecida e de maior visibilidade e E3 como um meio menos prestigiado por ser um canal do Youtube para um público específico, enquanto E2 se situa entre os dois, já que, embora 0 jornal francês tenha alta divulgação e visibilidade, 0 modelo da entrevista analisada sugere interação mais informal, em que o entrevistado tem mais espaço do que em uma entrevista para circulação em TV aberta, por exemplo. Em todas elas, os assuntos circulam em uma mesma esfera: a carreira do cantor e suas influências e assuntos de cunho social como racismo e desigualdade de classes.

A primeira categoria - léxico como marcador de intensidade - apresenta a utilização do léxico obsceno em gírias para indicar intensidade e, por vezes, modo, isto é, cumprindo função gramatical de advérbio. A locução pra caralho, variando em pa/pra/ para e carai/caraio/caralho, cumpre no dialeto gírio da capital paulista a função de intensificador, atuando como uma expressão adverbial de intensidade. A seguir, exemplifica-se 0 uso efetivo da expressão em seu contexto.

(1) [...] se o Estado é violento o povo vai ser violento e vice-versa ta ligado? como a gente constrói uma ponte aonde $0:$ : $0 \ldots . .:: 0$ afeto circule e a gente consiga alcançar uma sociedade melhor é uma resposta complexa pa caralho num país que nem o Brasil que é um barril de pólvora mano...tendeu? agora 0 que minha música bate $\mathrm{e}$ bate PA CARAI na tecla é... enquanto tiver só um grupo de cara branco em

\footnotetext{
As três entrevistas serão tratadas respectivamente por E1, E2 e E3: E1: Conversa com Bial - Emicida \& Rael [COMPLETO], 44:47. <https://youtu.be/109ea4x20LQ> Publicado em 18 nov.2017/ Ultimo acesso em 23 set.2018. 2: Emicida: livre, emocional e selvagem: Entrevista completa, 22:42. <https:// youtu.be/Wk2TE2Yvjlk> Publicado em 16 mai.2018/ Ultimo acesso em 23 set.2018. E3:PROGRAMA FREESTYLE COM EMICIDA, 48:06. <https://youtu.be/mdr3rXS3Npw> Publicado em 8 set.2016/ Último acesso em 23 set.2018
} 
volta da mesa lá mano...ceis tão indo pro caminho oposto ao da solução (E2, $3: 48)$

A palavra caralho já aparece em alguns dicionários com a definição além da literal, no entanto, seu sentido principal ainda é considerado tabu por nomear o órgão genital masculino. Aparece no dicionário Michaelis online ${ }^{6}$ como substantivo masculino pertencente à linguagem vulgar, "pênis", sendo, portanto, um léxico de caráter obsceno por fazer menção ao órgão sexual de forma literal e objetiva. É assim também registrado no dicionário online Priberam ${ }^{7}$ no qual é classificado como tabuísmo e definido como "órgão sexual masculino = PÊNIS".

Apesar de seu caráter como tabu linguístico, a palavra vem sendo constantemente ressignificada e adequada a novos contextos de uso, como nas gírias, que aqui são objeto de estudo, nas quais 0 item obsceno se desprende de seu sentido ofensivo. Em (1), por exemplo, a locução aparece em duas formas diferentes, pa carai e pa caralho, sendo que, em ambas, pelo contexto, podiam ser facilmente substituídas por um advérbio de intensidade ou sua locução correspondente.

Nesse aspecto, é importante se valer do que sustenta Martelotta (2011, p. 107) ao tratar dos parâmetros de mudança linguística em processos de gramaticalização, em específico, no que se refere à extensão ou generalização de contextos, como é 0 caso do exemplo analisado aqui: "caracteriza-se pelo desenvolvimento de usos em novos contextos. Os elementos envolvidos no processo assumem, com a mudança, um novo conjunto de contextos de uso, assim como as características estruturais deles decorrentes".

Como se observa em mais três exemplos selecionados do corpus:

(2) [...] e aí eu comecei a fazer - - eu fiquei viajando ali mano que eu fiquei

"Caralho I Michaelis On-line." http://michaelis.uol.com.br/busca?id=GjwG. Acesso em 22 set.2018.

"Significado / definição de caralho no Dicionário Priberam da Língua...." https://www.priberam.pt/dlpo/caralho. Acesso em 22 set.2018. feliz pa carai... ta ligado?... porque PORRA mano se olhasse minha vida dois anos antes... eu tava num::: no último busão ta ligado? no último banco do último busão no terminal Santana ta ligado? (E2, 6:31)

(3) [...] me preocupa um momento também - - isso é uma parada louca assim refletindo sobre a arte me preocupa pa caralho esse momento onde a poesia precisa ser óbvia pa caralho... tá ligado mano? (E2, 12:00)

(4) [...] o tiozinho meteu essa aqui ó... ceis ta andando muito com os branco... ((risada)) aqui a gente ainda acredita na palavra das pessoa... ((risada)) nós rio pa caralho mano tendeu? (E2, 18:05)

Em nenhum deles, o contexto mantém relação com a semântica que a palavra carrega inicialmente como léxico considerado tabu, assim como em nenhum dos atos de fala nos quais está inserida há a proposta de ofensa, repreensão ou xingamento, o que remete à confirmação de que a palavra foi imersa em um novo contexto de uso, corroborando a tese defendida neste artigo de neologia pragmática a partir de novos arranjos semânticos.

Nesse ponto, para observar esse tipo de mudança, devem ser considerados os aspectos semântico, sociolinguístico e, em especial, 0 pragmático-discursivo. À luz da sociolinguística, as mudanças partem de um indivíduo e se estendem para os demais falantes, o que encaminha diretamente ao conceito de gíria como algo criado como código secreto de uma comunidade de fala, podendo ou não se estender para 0 coletivo.

Semanticamente, pensa-se na atribuição de novos valores ou referências a um item lexical, contudo, é a partir da esfera pragmático-discursiva que surge essa nova valoração quando o item passa a ser utilizado em novos contextos de interação, sendo seu uso, nesse caso, de um grupo de fala com léxico gírio, em que há a 
possibilidade de essa nova construção figurar cada vez mais em outros novos contextos sociais, inicialmente, similares.

A segunda categoria - gíria com léxico obsceno funcionando como interjeição - investiga como, em um léxico gírio, palavras consideradas tabu figuram como interjeições nas frases. Neste recorte, dois palavrões são os utilizados mais comumente nessa função: caralho e porra. A primeira palavra já teve sua definição explorada anteriormente, já a segunda é registrada em dicionários ${ }^{8}$ como "Clava constituída de um pau curto com cabeça de ferro, porrete; pênis; esperma" e "Pau comprido e arredondado. = CACETE, MOCA, PORRETE; coisa ou .fato. incômodo. = PORCARIA; pênis; esperma, sêmen".

Mais uma vez, como com os dois casos anteriores, a palavra considerada tabu é imergida em novos contextos (extensão) a partir dos quais perde a carga semântica ofensiva (dessemantização) e passa a carregar novos valores semânticos, como exemplificado a seguir.

(12) [...] eu peguei uma fase assim... eu eu... sempre brinco com isso eu falo... eu cresci vendo Leandro e Leonardo indo no Faustão ((imitando a voz do apresentador)) e venderam...trinta milhões de cópias: e tipo disco de ouro pra todo mundo aí na vez do Emicida ninguém compra disco mais ta ligado? mano eu falei tipo... CARALHO bem na minha vez mano? ta ligado? (E1 13:02)

Em (12), a palavra caralho passou pelo processo de extensão e por uma dessemantização de seu teor ofensivo, todavia a mudança de classe de palavras, no caso do palavrão como interjeição, é um fenômeno muito significativo, uma vez que revela um fenômeno de mudança linguística de base categorial (ou decategorização), como atesta Martelotta (2011, p.

\footnotetext{
${ }^{8}$ A fonte dos verbetes é, respectivamente: 1. "Porra = Michaelis On-line." http://michaelis.uol.com.br/bus$c a ? r=0 \& f=0 \& t=0 \&$ palavra=porra. Acesso em 23 set.2018. 2. "Significado - definição de porra no Dicionário Priberam da Língua [...]" http://dicionario.priberam.pt/porra. Acesso em: 23 set.2018.
}

108-109), em que ocorre a "perda de propriedades típicas das formas fonte, com a aquisição de novas características morfossintáticas ou discursivas", isto é, acontece uma mudança de classe gramatical. Podese amparar também em Ullmann (1977), que sobre a origem dos tabus linguísticos, classifica um de seus tipos ocorrendo por ações de transgressão às leis de decência e de decoro, ou seja, que abarca referências sexuais.

Outro ponto em relação às interjeições refere-se ao fato de que não é uma questão apenas de ordem morfológica, mas da força ilocucionária que ganha e, em consequência, da função sintáticodiscursivo-pragmática decorrente disso, como nos exemplos abaixo:

(13) [...] aí o mano tomou um susto lá do outro lado ta ligado? falou CARALHO... mas e aí comé/ que resolve? (E2 6:05)

(14) e aí eu comecei a fazer - - eu fiquei viajando ali mano que eu fiquei feliz pa carai... ta ligado?... porque PORRA mano se olhasse minha vida dois anos antes... eu tava num::.: no último busão ta ligado? no último banco do ultimo busão no terminal Santana ta ligado? (E2 6:31)

(15) cê acha que um dos requisito pra ser poeta é tá morto...quem me mostrou que a poesia é um bagui pra gente viva foi o Sérgio Vaz...eu falei CARALHO o maluco é poeta e tá vivo mano?... eu achei FODA...tendeu? (E2 11:09)

(16) [...] comé/ que é?... é:: "vai que vai... na febre não se ilude"... é::: CARALHO mano... peraê/ (E3 10:21)

(17) F1: [...] e foi longe o negócio heim?

(18) F2: porra:.: moleque [...] (E3 3:07) 
(19) [...] acho que a primeira vez que escreveram bacana assim um texto que eu me lembro de ter visto um texto que eu achei FODA assim foi quando... no Per Raps falou da triunfo... ta ligado? isso aí eu lembro até hoje assim que eu li e falei CArai saí no Per Raps, mano:: (E3 8:42)

(20) [...] José Eduardo Agualusa?... José Eduardo Agualusa é isso?...NÃO... é::: PORRA mano não lembro agora... não é José Eduardo é o nome do presidente de Angola:: é::.....PORRA é Agualusa...conhecido como Agualusa [...] (E3 21:59)

(21) [...] boy... ES-CA-LA-DA truta? CARAI MARCÍLIO...mano ce fala duas línguas mano ce tava em Minas fazendo escalada truta [...] (E3 43:39)

Constata-se, assim, que a decategorização das palavras porra e caralho, passando de substantivos a interjeições, projeta nelas um maior potencial de mobilidade dentro da oração, a necessidade pragmático-discursiva faz com que elas percam as antigas restrições de caráter morfossintático como substantivos e que a entonação enfática dada a essas unidades lexicais nesse contexto de uso prova mais uma vez como o neologismo semântico-pragmático desencadeia uma série de mudanças formais e/ou semânticas.

Em (19), por exemplo, a palavra porra aparece duas vezes como interjeição enquanto 0 entrevistado tenta se lembrar do nome do autor de um livro, em ambas as vezes, assim como na maioria dos outros casos registrados, é dada maior ênfase (marcada pelas maiúsculas) à palavra que está cumprindo função de interjeição, sendo ela fator importante tanto para a inserção da unidade lexical nesse novo contexto quanto para sua ressignificação semântica, isto é, caso o palavrão estivesse em sentido "original" em um contexto de ofensa ou xingamento, a ênfase não funcionaria da mesma maneira como quando está exercendo o papel pragmático de interjeição.

Na terceira categoria - adjetivação a partir de léxico obsceno, sustenta-se que, por carregarem sentido obsceno, ofensivo ou feridor da moral, os palavrões podem ser utilizados com seu sentido original em xingamentos e, muito facilmente, figurar como adjetivos, entretanto, a perda da carga ofensiva os situa de outra forma na interação. Uma utilização muito comum da palavra foda em gírias diz respeito justamente a essa adjetivação sem a carga semântica ofensiva, por exemplo,

(5) [...] porque toda vez que alguém vai se referir ao jeitinho brasileiro fala duma malandragem duma/ picaretagem e reduz 0 jeitinho brasileiro a isso... 0 jeitinho brasileiro... ele é minha mãe mano... que tem milhões de pessoas que faz isso aí ta ligado? tipo essa é a parada mais foda do Brasil e que infelizmente fica (invisível) [...] (E1, 18:30)

Em (5), o rapper explica ao entrevistador como acha ruim a constante associação do estereótipo brasileiro com a malandragem ou a picaretagem e que, para ele, o verdadeiro jeitinho brasileiro é de alguém como sua mãe, que, como ele cita em outro momento, seria alguém que trabalha e se empenha muito para enfrentar a vida. 0 estado do entrevistado de discordância fica mais claro quando ele adjetiva a situação, que ele denomina de "parada", fazendo a escolha por usar a palavra foda para tal circunstância.

0 verbete para essa palavra traz de imediato o seu significado literal, isto é, sua carga semântica obscena que é amplamente conhecida e sua categorização como tabu linguístico. No dicionário Michaelis online ${ }^{9}$ e no dicionário Priberam da Língua Portuguesa ${ }^{10}$, as definições de fodasão respectivamente "Ato de foder; cópula, metida, pingolada, trepada." e " Relação ou ato sexual. = COITO, CÓPULA".

9 "Foda I Michaelis On-line." http://michaelis.uol.com.br/busca?id=Mmko. Acessado em 23 set. 2018.

10 "Significado: definição de foda no Dicionário Priberam da Língua [...]" https://www.priberam.pt/dlpo/foda. Acessado em 23 set. 2018. 
Dadas as definições dicionarizadas da palavra, fica posto que ela, ao ser inserida nesse contexto gírio, foi submetida a outros contextos de uso que não 0 previsto para 0 seu significado inicial, logo, como a palavra caralho, analisada anteriormente, ela passou pelo processo de extensão e, em esfera pragmáticodiscursiva, a ser utilizada em outros contextos, o que leva a um outro conceito levantado por Martelotta (2011) a partir do qual é possível entender melhor como se configura o uso desse palavrão como gíria:

[a dessemantização ou redução semântica] Caracteriza-se pela perda de conteúdo semântico. [...] Ocorre que, ao ser utilizado em novos contextos (extensão), 0 elemento tende a perder seu sentido original ao ser reinterpretado nesses novos contextos: 0 uso de uma expressão linguística $X$ em um contexto $Y$ implica que $X$ perca parte de seu sentido original, ou seja, aquele que é incompatível com Y. (MARTELOTTA, 2011, p. 108)

É, portanto, com a utilização da palavra na interação e inserindo-a em novos contextos que se viabiliza sua ressignificação, o que mostra sua configuração de uso como um neologismo semântico-pragmático, ampliado semanticamente. Nesse aspecto, vale lembrar Alves (2002) que observa ser 0 neologismo parte da história das línguas, evidenciando sua vitalidade, além de sustentar que uma das possibilidades de configuração de entidades neológicas justamente está na semântica e na pragmática.

Abaixo, outros seis exemplos selecionados das entrevistas:

(6) [...] você recebe a música dum jeito... uma mina loira em Alphaville recebe a música de outro jeito e nenhuma dessas visão é menos verdadeira do que a outra... só tem menos 0 direito de existir na cabeça de quem ta preso num:: modo () de trinta quarenta cinquenta anos atrás... esse bagulho é FODA [...] (E2 13:11)
(7) [...]se sua vida não tem valor porque que cê vai valorizar a dosoto/... ta ligado?... então é isso o Brasil precisa pensar em quem ta la na beirada...ta ligado? quanto mais pessoa tiver caindo de la mano... mais arriscada de quem ta aqui...sacou? nesse ponto é foda (E2 21:12)

(8) [...] eles nunca se incomoda quando eles vê um preto na calçada ta ligado? eles nunca se incomoda quando eles vê um preto jogado no meio do LIXO andando pelado LOUco na rua amontoado nas cadeia ta ligado?... mas aí ganhando 0 troféu de homem do ano na música... com um terno...FODA e tava TODO MUNDO na festa com um terno foda e só 0 meu virou::...0 motivo da polêmica... sacou? (E2 1:18)

(9) cê acha que um dos requisito pra ser poeta é tá morto...quem me mostrou que a poesia é um bagui pra gente viva foi 0 Sérgio Vaz...eu falei CARALHO o maluco é poeta e tá vivo mano?... eu achei FODA... tendeu? (E2 11:09)

(10) [...] ele fala uma parada muito foda sobre a laboratório fantasma né? nem sobre só eu enquanto pessoa...ta ligado? salvar 0 mundo é uma tarefa hercúlea ta ligado mano? é um bagulho gigante mano é uma parada...que:.: é um esforço memo que:.: eu não sei que tamanho é 0 esforço que cê precisa fazer pa salvar 0 mundo 0 planeta inteiro...mas existe 0 salvar OS MUNDOS...ta ligado mano?... e as vezes você salva 0 mundo de uma pessoa...ta ligado? (E2 21:46)

(11) [...] acho que a primeira vez que escreveram bacana assim um texto que eu me lembro de ter visto um texto que eu achei FODA assim foi quando... no Per Raps falou da triunfo... ta ligado? isso aí eu lembro até hoje assim que eu li e falei CArai saí no Per Raps...mano:: (E3 8:42) 
Uma leitura das frases nas quais figura 0 inicialmente palavrão evidencia como, depois de perder a carga semântica obscena e ser utilizada como uma gíria com carga semântica modificada estabelecendo-se como um neologismo semântico, o léxico é ressignificado a partir do contexto de uso. Entre (5) e (7), foda funciona como adjetivo, mas designa caráter negativo em relação ao substantivo 0 qual qualifica, enquanto a adjetivação, entre (8) e (11), tem valor positivo. Com isso, salienta-se que, embora a palavra receba nova valoração semântica depois de perder o teor ofensivo ou obsceno, é apenas a partir da interação e seu respectivo uso que esses novos valores semânticos são trazidos ao léxico e à própria lexia, em especial nesse contexto de gíria no qual, por ser inicialmente um vocabulário exclusivamente secreto, a compreensão da palavra no contexto significa a identificação e inclusão do indivíduo naquela comunidade de fala.

Nesse ponto, é possível ratificar a tese defendida neste artigo, visto que a utilização de léxico obsceno em gírias com função de adjetivação demonstra 0 caráter extremamente pragmático da negociação constante de sentido entre os interactantes no ato da fala. Como já explicitado, é o contexto de interação que vai determinar se foda como adjetivo carrega valoração positiva ou negativa e, ainda, que os interactantes só farão tal escolha caso desejem que a palavra tenha uma construção semântica que ratifique sua escolha, visto que há uma negociação mútua acontecendo na interação.

Nesse trajeto de investigação, no que se refere às três categorias elaboradas para a análise do corpus selecionado, verifica-se que o léxico obsceno migra para um uso como vocábulo gírio, remetendo a escolhas neológicas de ampliação semântica, com base pragmática ao estabelecer novas possibilidades de sentido. Para além, envolve-se nesse processo 0 léxico, a gíria, o neologismo, a linguagem obscena e o tabu linguístico como elementos sociolinguísticos, sustentando que a mudança linguística ressoa no sistema linguístico.

\section{CONCLUSÃo}

Chega-se à conclusão, neste artigo, de que 0 aspecto semântico-pragmático considerado como neologia constituída a partir de um uso de léxico obsceno que se "empresta" a uma categorização de gíria com a ampliação de seu sentido é abonado pela sociolinguística variacionista, no postulado de Weinreich, Labov e Herzog (2006, p. 17) com relação aos fatores condicionantes identificados, à transição, ao encaixamento, à avaliação e à implementação, ao se constituir como fatores que sustentam se e em que fase uma mudança linguística está.

Nesse ponto, cumpre ressaltar que a coleta não é suficiente para balizar uma afirmação certeira de mudança linguística em fase de implementação, todavia indicia, sim, que os demais fatores estão em condições de se constatar como processos em andamento, como fatores condicionantes - grupo do qual o entrevistado faz parte, transição - estruturas linguísticas que se generalizam e/ou que se decategorizam e/ou que se dessemantizam, encaixamento - conforme a matriz contínua de comportamento sociolinguístico e avaliação - espaços ocupados pelo entrevistado em diferentes tipos de público com a manutenção de sua linguagem obscena independentemente disso, ainda que com maior monitoramento em algumas situações, validando seu sentimento de pertença.

A partir das reflexões explicitadas ao longo do artigo, torna-se evidente que a utilização de léxico obsceno como gírias, em sua construção na variante paulista, demonstra que a cortesia e os bons modos são mantidos durante a interação na qual o palavrão aparece, o que comprova a perda de valor ofensivo do vocábulo, sua imersão em novos contextos e sua ressignificação de sentido compreendida pelos interactantes. Apesar disso, há um possível monitoramento da fala quanto ao uso de gírias com palavrões dependendo do nível de prestígio e formalidade, desse modo, E1 registrou apenas duas ocorrências de léxico obsceno, em oposição a E2 com 12 ocorrências e E3 com seis. No entanto, esse uso, seja em menor ou maior número, não prejudicou a 
interação ou causou desacordo entre entrevistador e entrevistado.

Por fim, reitera-se que 0 fenômeno do neologismo semântico-pragmático serve à negociação de sentido entre interactantes nos diversos atos de interação, pois valendo-se do contexto, no caso do léxico gírio, da comunidade de fala à qual a gíria pertence, eles podem buscar o que melhor os ajuda no processo sociocomunicativo, mesmo que isso signifique propor um novo uso de um léxico já conhecido.

\section{REFERÊNCIAS}

ALVES, I. M. Neologismo: criação lexical. São Paulo: Ática, 2002.

ANDRADE, M. M. Lexicologia, terminologia: definições, finalidades, conceitos operacionais. In: OLIVEIRA, A. M. P. P.; IZQUERDO, A. N. (Org.). As ciências do léxico: lexicologia, lexicografia, terminologia. Campo Grande/ MS: Ed. UFMS, 1998, p. 189-198.

BARRERE, L. L. Face e polidez linguística em reclamações online: uma análise sob o viés pragmático. Entrepalavras, Fortaleza, v. 7 , p. $383-405$, jan./ jun.2017.

BIDERMAN, M T. C. Fundamentos da Lexicologia. In: TEORIA linguística: teoria lexical e linguística computacional. São Paulo: Martins Fontes, 2001. p. 99-155.

BIDERMAN, M. T. C. Léxico e vocabulário fundamental. Alfa, São Paulo, v. 40, p. 27-46, 1996.

BONA, A. II turpiloquio nel serial: approccio alla traduzione. Milano: 2008, 54f. Tesi di laurea. (Laurea in Mediazione Linguistica e Culturale) - Università degli Studi di Milano. Disponível em: <http://www.focus.it/ Community/cs/blogs/vito_dixit/default.aspx>. Acesso em: 24 set.2018.

CRYSTAL, D. Dicionário de linguística e fonética. Rio de Janeiro: Jorge Zahar, 2000.

GUERRA, M. M.; ANDRADE, K. de S. 0 léxico sob perspectiva: contribuições da Lexicologia para 0 ensino de línguas. Domínios da Linguagem. v. 6, n. 1, 2012. p. 226-241.

GUMPERZ J. J. Discourse strategies. Cambridge: Cambridge University Press, 1982.

LABOV, W. Padrões sociolinguísticos. Tradução Marcos Bagno, Maria Marta Pereira Scherre e Caroline Rodrigues Cardoso. São Paulo: Parábola, 2008.

LEVINSON, S. C. Pragmática. São Paulo: Martins Fontes, 2007.

MARTELOTTA, M. E. Mudança linguística: uma abordagem baseada no uso. São Paulo: Cortez, 2011.

ORSI, V. Tabu e preconceito linguístico. ReVEL, v. 9, n. 17, 2011. p. 334-348.

ORTíZ ALVAREZ, M. L. 0 léxico como expressão de identidade cultural. Anais do 52 GEL. Campinas: Mercado de Letras/IEL: 246, 2004.

PEREIRA, M. G. D. Introdução: palavra (PUCRJ), Rio de Janeiro, n. 8, p. 7-25, 2002.

PRETI, D. A gíria e outros temas. São Paulo: T. A. Queiroz, 1984.

TRASK, R. L. Dicionário de linguagem e linguística. São Paulo: Contexto, 2004. 368p.

ULLMANN, S. Semantic universals. In: GREENBERG, J. Universals in language. Massachusetts: MIT Press, 1966.

ULLMANN, S. Semântica: uma introdução à ciência do significado. Lisboa: Fundação Calouste Gulbenkian, 1977.

WEINREICH, U.; LABOV, W.; HERZOG, M. I. Fundamentos empíricos para uma teoria da mudança linguística. São Paulo: Parábola, 2006. 